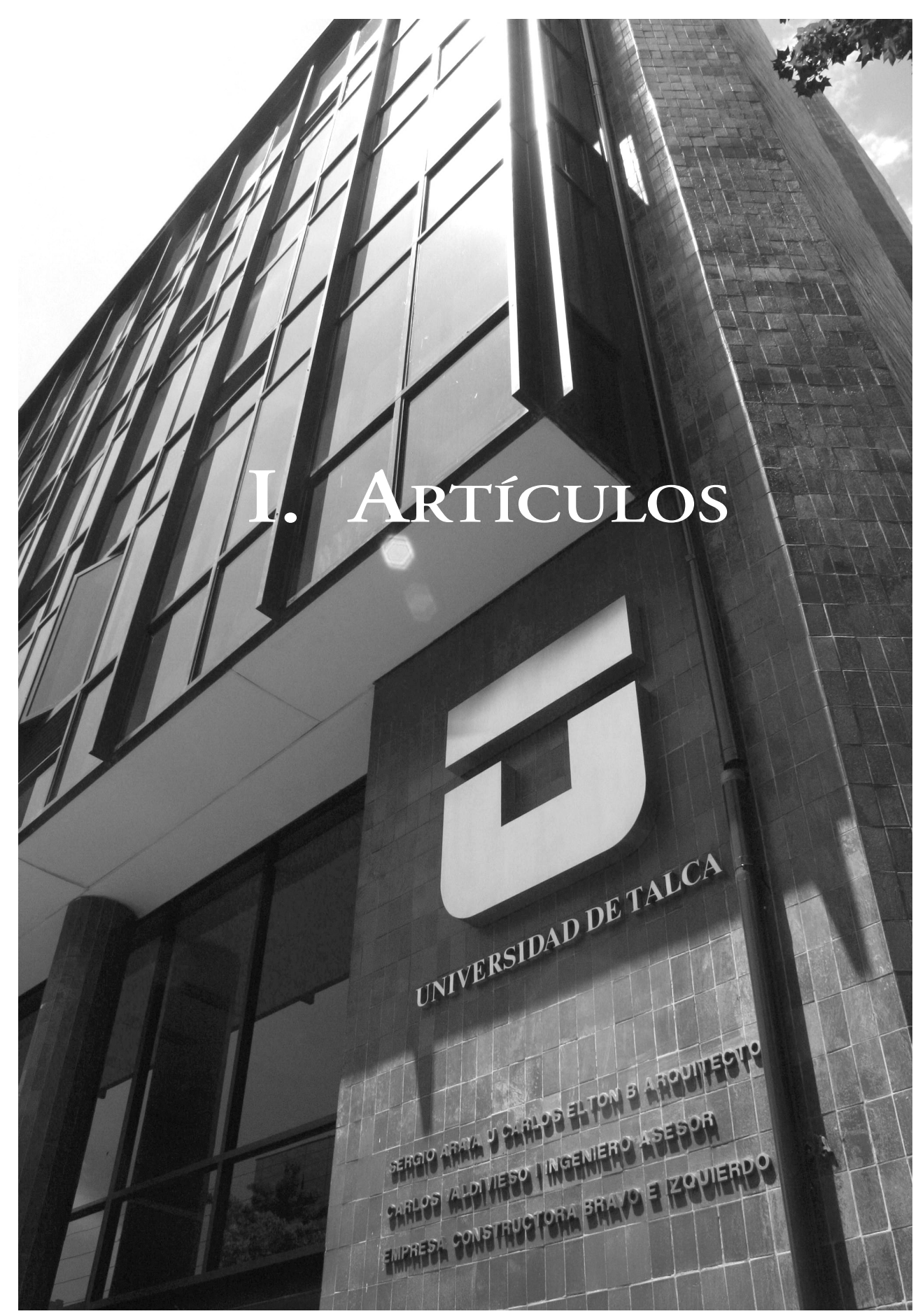

Campus Santiago, Universidad de Talca,

donde se ubica el Centro de Estudios Constitucionales de Chile 

Estudios Constitucionales, Año 11, No 2, 2013, pp. 15 - 46.

ISSN 07180195

Centro de Estudios Constitucionales de Chile Universidad de Talca

"La pretensión de objetividad como una estrategia para obligar. La construcción de cierta cultura de hermenéutica constitucional hacia fines del siglo XX"

Jaime Bassa Mercado

\title{
LA PRETENSIÓN DE OBJETIVIDAD COMO UNA ESTRATEGIA PARA OBLIGAR. LA CONSTRUCCIÓN DE CIERTA CULTURA DE HERMENÉUTICA CONSTITUCIONAL HACIA FINES DEL SIGLO XX*
}

\author{
THE PRETENTION OF OBJECTIVITY AS A STRATEGY TO ENFORCE. \\ THE CONSTRUCTION OF A CERTAIN CULTURE OF CONSTITUTIONAL \\ HERMENEUTIC AT THE EDGES OF THE 20 ${ }^{\mathrm{TH}}$ CENTURY
}

\author{
Jaime BASSA MERCADO** \\ Universidad de Valparaíso - Chile \\ jaime.bassa@uv.cl
}

RESUMEN: El presente trabajo explica cómo la interpretación constitucional tiene una dimensión politica, en la que se relaciona determinada hermenéutica con el proyecto político plasmado en la Carta durante la dictadura. Se trabaja una referencia al periodo codificador del siglo XIX, donde se aprecia una relación entre un proyecto politico plasmado normativamente y ciertas estrategias destinadas a protegerlo, como las reglas de interpretación de la ley. Parte del constitucionalismo chileno, concretamente durante las primeras décadas de la Carta vigente, muestra su compromiso con una estructura similar: un catálogo de derechos fundamentales casi sin modificaciones junto a criterios de interpretación constitucional que petrifican su contenido.

ABSTRACT: The paper explains how the current constitutional interpretation has political matrixes, relating certain constitutional interpretation to the political program of the Constitution itself, during the Dictatorship. It develops a reference to the codifier period on 19th century, which shows a relation between a political program written into the law and certain strategies toward it protection, such as the rules for legal interpretation. Some Chilean constitutionalism, especially during the first decades of the current Constitution, shows a commitment with a similar structure: an unmodified catalogue of fundamental rights attached to criteria of constitutional interpretation that petrify its content.

PaLABRAS CLAVE: Interpretación Constitucional, Originalismo, Derechos Fundamentales

KEY WORDS: Constitutional Interpretation, Originalism, Fundamental Rights

\footnotetext{
* Artículo preparado en el marco del Proyecto Fondecyt No 11110290, del cual el autor es investigador principal. Agradezco los aportes y comentarios críticos de los profesores Nicolás Fuster, Javier Valle, Christian Viera y Luis Villavicencio, así como al profesor Pablo Ruiz-Tagle y a los asistentes al seminario del Doctorado en Derecho de la Universidad de Chile, por sus valiosos aportes críticos. Trabajo recibido el 26 de septiembre de 2012 y aprobado el 22 de mayo de 2013.

** Doctor en Derecho por la Universidad de Barcelona, España; Magíster en Derecho, mención en Derecho Público, por la Universidad de Chile; Licenciado en Derecho por la Universidad Católica de Chile. Profesor de Derecho Constitucional de la Escuela de Derecho de la Universidad de Valparaíso, Chile.
} 


\section{INTRODUCCIÓN}

La interpretación constitucional chilena estuvo marcada por una fuerte tendencia al originalismo, que ancla la determinación del sentido y alcance de la Constitución a las Actas de la Comisión de Estudios para la Nueva Constitución (CENC, 1973-78). Este originalismo tiene dos importantes elementos que no han sido suficientemente evidenciados: en primer lugar, sus claros fines políticos, toda vez que ha sido utilizado para proteger la obra constitucional de la dictadura $y$, en segundo lugar, sirvió como un argumento de autoridad para zanjar complejas discusiones (políticas y, muchas veces, valóricas) en torno a la interpretación de la Constitución vigente y a su desarrollo legislativo. Es en esta última dimensión donde se centra el presente estudio: la interpretación constitucional históricamente predominante durante las primeras décadas de la Constitución vigente se presentó como el método idóneo para determinar su verdadero sentido; consecuencialmente, se asumió que es posible identificar una única interpretación correcta de la norma. Así, se reviste de objetividad y neutralidad tanto al criterio hermenéutico como a su resultado, dotándolo de intangibilidad frente a críticas y cuestionamientos.

Es posible identificar ciertos hitos históricos que han influido en la construcción de la cultura jurídica chilena, formada por una serie de modelos históricos que han sido incorporados a través de ciertas instituciones normativas, incidiendo directamente en su interpretación. No se pretende reconstruir un devenir histórico lineal y coherente siguiendo grandes categorías de épocas o siglos, sino identificar cambios de modelos o fenómenos de ruptura que han incidido en la estructura actual de la cultura jurídica chilena; tampoco se busca, por tanto, una reconstrucción dogmática de la interpretación constitucional ${ }^{1}$. Esta cultura se construye sobre la premisa que las instituciones jurídicas o bien son objetivas, o bien tienen una única interpretación correcta posible. De esta manera, se ha constreñido la labor legislativa a través del control de constitucionalidad y, de paso, la función de los estudiosos del derecho se ha limitado, por décadas, a la dogmática del texto escrito.

Así, en el Capítulo I se revisa críticamente la idea (o posibilidad) de objetividad en el conocimiento jurídico, con el fin de dar un marco conceptual al trabajo, pero sin constituir su objeto principal. El Capítulo II tiene por finalidad individualizar ciertos hitos o cambios históricos de la pretensión de objetividad en la aplica-

\footnotetext{
1 Para cumplir con los objetivos de la investigación, se ha adoptado la metodología de trabajo y análisis crítico expuesta en Foucault (2011a), pp. 12 ss.
} 
ción e interpretación del Derecho, enfatizando las dicotomías de cada categoría y el efecto que han generado en la cultura jurídica chilena y, en definitiva, en el ordenamiento jurídico. Se trata de un trabajo instrumental para los objetivos de la investigación. En el Capítulo III se identifican y caracterizan sólo dos de las principales manifestaciones de la pretendida objetividad de la hermenéutica constitucional, concretamente en materia de derechos fundamentales, el originalismo y la jerarquización de los derechos, para una caracterización de la interpretación de constitucional durante las primeras décadas de su vigencia.

\section{LA OBJETIVIDAD COMO ARGUMENTO}

La cuestión acerca de si la objetividad es posible en el conocimiento jurídico y cómo se manifiesta aquélla desborda las pretensiones del presente trabajo. Por ello, el punto de partida es la diferencia que existe entre el enunciado normativo y la norma, entendiendo por tal el significado que se le atribuye a aquél a través de la interpretación.

Así, asumo que existe una diferencia entre el enunciado normativo y la norma propiamente tal, es decir, entre el tenor literal de una disposición y el Derecho que se aplica en virtud de ella. En virtud de lo anterior asumo, también, que la objetividad en el conocimiento jurídico se limita a la identificación del tenor literal de la disposición escrita y no a su aplicación; la interpretación supone una transformación del objeto por la subjetividad del intérprete, quien lo hace suyo para después operar intersubjetivamente con el resultado de su proceso cognitivo, que intentará objetivar ${ }^{2}$. Es decir, la aplicación concreta del enunciado normativo supone una construcción argumentativa a partir de la cual el sujeto formula una interpretación determinada e intenta convencer que se trata de la correcta. En este proceso, el sujeto puede ser parcial o imparcial, es decir, puede mostrar diferentes niveles de compromiso con el objeto de estudio y, asimismo, puede ser más o menos consciente de aquello (Kennedy le llama disonancia cognitiva ${ }^{3}$ ).

Lo propio puede decirse tanto respecto de la objetividad en las decisiones judiciales como en el trabajo que realiza la doctrina. En cuanto a la primera, puede haber objetividad en el reconocimiento de la decisión en sí misma y de su contenido o estructura argumental, mas no en la relación que, en términos de corrección o de verdad, podría existir entre ésta y el enunciado normativo a

2 Maturana (2007). Respecto de la interpretación jurídica, Quintana (1994), pp. 89 ss.

3 Kennedy (2010), pp. 54 ss. 
partir del cual se construye. La valoración de las normas aplicadas se encuentra influida por las particularidades del sujeto, toda vez que la pretendida claridad en el proceso de subsunción se difumina en un cada vez más complejo ordenamiento jurídico. Conocida es la vieja propuesta de Dilthey: el intérprete entiende mejor el texto que su autor.

El contenido de la decisión judicial también supone un cuestionamiento a la objetividad de la interpretación, no sólo porque es interpretable en sí mismo, sino porque pudo haber sido diferente sólo alterando algunos factores inherentes al sujeto, o bien, en la valoración que hizo de los materiales disponibles. Su contenido se encuentra más determinado por las características personales del intérprete que por la literalidad del enunciado normativo, del cual no se desprende una respuesta necesaria y correcta. Por el contrario, desde él se proyectan una serie de soluciones posibles, alguna o algunas de las cuales podrán ser adecuadas para determinado caso, así como otra será mejor considerada por el propio sujeto que la aplica. Me encuentro entre quienes asumen que tras la norma no hay una única respuesta correcta, sino diversos significados que podrán ser adjudicados con mejores o peores argumentos; así, la interpretación jurídica se asemeja más a lo que Guastini llama "interpretación decisión" antes que a la "interpretación conocimiento" ${ }^{4}$. Esto es particularmente evidente cuando la interpretación la realiza un órgano colegiado, como lo demuestra la presencia de votos de minoría.

Lo anterior puede predicarse, con la misma o mayor propiedad, respecto de la doctrina: comenzando desde un enunciado normativo común, lo que se dice de él obedece a la combinación de una serie de opciones que el sujeto toma frente a su objeto de estudio (metodológicas, epistemológicas, hermenéuticas, políticas) que condicionan el resultado de su labor. Así, considerando la importancia de estas opciones en el contenido de su trabajo, es posible afirmar que existe más derecho constitucional en los libros que en la Carta. En efecto, dado que la indeterminación del derecho es todavía más evidente en la apertura de las normas constitucionales, la interpretación es clave para la concretización de su contenido normativo que, en ningún caso, es autoevidente 5 .

4 GUASTINI (1999), pp. 203-204. Sobre el escepticismo ante la interpretación judicial (es decir, de la elección que hace el juez de la interpretación que finalmente aplica), MarTí (2002), pp. 263 ss.

5 Esta indeterminación de las normas constitucionales puede tener dos lecturas, una que sospecha de la discrecionalidad de los jueces en la interpretación constitucional (Aldunate, 2010) y otra que celebra la garantía de libertad política del legislador en la interpretación constitucional (HESSE, 2011) las que no son, necesariamente, excluyentes entre sí. 
Esta concretización se realiza una vez que el intérprete ha definido una postura, con mayor o menor conciencia, sobre una serie de materias: opciones metodológicas propias de la disciplina; política contingente; rol del Estado en la sociedad y en la economía; concepciones acerca de la Constitución como norma fundamental, el origen legítimo/ilegítimo de la Carta chilena vigente, el contenido de ciertas instituciones (como la familia, la igualdad o la propiedad), la justicia (distributiva, formal, material); en fin, acerca de la interpretación constitucional: originalista o evolutiva. Cada una de estas materias lleva al jurista, al académico y al docente a definirse frente a las alternativas que ellas contemplan. El enunciado precedente da cuenta de la multiplicidad de combinaciones posibles a partir del texto constitucional y, en consecuencia, de las diversas aproximaciones de quien lo estudie.

Lo anterior genera resultados diferentes, en tanto que argumentativamente se puede justificar de diversas maneras el texto constitucional vigente. Ello explica, por ejemplo, que no todos interpretemos el artículo 19 No 1 inciso $2^{\circ}$ de la Constitución de la misma forma, ya que no existe consenso sobre si la vida del que está por nacer tiene protección constitucional o sólo legal, si se trata de un derecho fundamental o de un interés constitucional, etc. El contenido material de dicho enunciado no es autoevidente. La norma se construye a partir de interpretaciones que, a su turno, contarán con mejores o peores argumentos. El contenido de la norma es su interpretación; ni correcta ni incorrecta, sino mejor o peor argumentada, lo que dependerá de las opciones que tome el intérprete. En definitiva, de una interpretación constitucional sólo podría decirse que se sostiene en mejores argumentos que la contraria.

Otro ejemplo de cuán importante es la dogmática nacional para la construcción del ordenamiento constitucional chileno, se encuentra en el artículo 19 No 21 inciso $2^{\circ}$ de la Carta, que establece el estatuto del Estado empresario. La disposición sólo establece una distribución de competencias a favor del legislador para determinar las condiciones en que el Estado podrá desarrollar actividades económicas. La doctrina nacional ha sostenido que se trata de una de las manifestaciones constitucionales del orden público económico, construido a partir del derecho de propiedad y del principio de subsidiariedad; es la doctrina la que dota de contenido material al enunciado normativo y lo configura como un estatuto de orden público y de rango constitucional ${ }^{6}$. Sin embargo, del referido artículo no se desprende ninguno de estos elementos, que tienen (o podrían tener) reco-

6 Fermandois (2006), pp. 72-74. 
nocimiento en otra disposición constitucional7. Si el constitucionalismo chileno concibe el estatuto del Estado empresario como lo hace, se debe exclusivamente a una dogmática constitucional que lo ha interpretado a partir de ciertos principios (subsidiariedad) en desmedro de otros (solidaridad), en respuesta a sus propias opciones políticas ${ }^{8}$.

\section{Aspectos fundamentales de la Codificación en Chile}

La cultura jurídica chilena se ha formado en un largo devenir histórico, que hunde sus raíces en el período romano; desde entonces, es posible identificar ciertos denominadores comunes en la forma como los intervinientes del fenómeno jurídico se relacionan con éste, formando progresivamente un sello cultural que se manifiesta tanto en algunas instituciones normativas de nuestro actual ordenamiento jurídico, como en ciertas categorías culturales relacionadas con su interpretación y aplicación.

De este proceso me interesa destacar ciertos momentos de quiebre, antes que reconstruir un relato lineal y pretendidamente racional; ello, porque existen antecedentes que tienen una significancia cultural en la actual concepción del Derecho, en particular su interpretación: $a$. en el Derecho Romano, la relación y diferencia que existe entre sus etapas clásica y vulgar, tanto desde la perspectiva de la creación del Derecho como desde su aplicación; b. en la recepción del Corpus Iuris Civiles, la evolución histórica que presentan las escuelas de glosadores y comentaristas, quienes desarrollaron metodologías de trabajo que se diferenciaban, principalmente, por su grado de apego al tenor literal de la norma; para, finalmente, llegar a $c$. en el modelo de la codificación, que viene a reemplazar al Derecho indiano, la prioridad conceptual que adquiere la noción de código por sobre la de ley en tanto fuente formal del Derecho durante el siglo XIX y la forma en que éste moldea culturalmente tanto a la doctrina como al ordenamiento jurídico.

\section{a. Derecho Romano: auctoritas y potestas}

Dentro de evolución histórica que presenta el Derecho Romano, me interesa destacar la relación que existe entre las etapas clásica y posclásica, en cuanto a los procesos de generación del Derecho y de su validación frente a la comunidad, es decir, las fuentes del derecho y sus criterios de validez.

7 Bassa y Viera (2012).

8 He trabajado este tema previamente en BASSA (2011b). 
El Derecho Romano durante su época clásica (130 a.C.-230 d.C.) se caracteriza por tratarse de un derecho de juristas, por cuanto de ellos dependen, preferentemente, tanto los criterios de resolución de conflictos jurídicos, como su validez. Movidos por el reconocimiento en la autoridad de su criterio (su saber socialmente reconocido) y no por el ejercicio de un cargo público, las personas recurren a los juristas para que conozcan y resuelvan sus conflictos. Así, los criterios de solución de los conflictos de relevancia jurídica no son impuestos por el poder político, sino que se construyeron por la comunidad a través de su proceso de formación, quien los legitimaba a partir de su socialización.

Se trata de un método bastante horizontal y colectivo para la generación del derecho, cuya legitimidad radica directamente en el reconocimiento que la comunidad le otorga al jurisconsulto y a los criterios que aplica y según su prudencia le ordenen. De esta manera, la comunidad no sólo conoce los criterios de solución de conflictos antes de recurrir a una instancia de resolución, sino que también los revisa y cuestiona, cuando elige determinado jurista en desmedro de otro. De esta manera, los juristas y sus criterios podían tener diversos grados de reconocimiento, permitiendo la consolidación de unos y forzando la desaparición de otros; así como ciertos criterios constituyen una opinión común y no controvertida entre los juristas (communis opinio doctorum), otros son paulatinamente desechados?.

Esta etapa clásica del Derecho Romano comienza a apagarse con la progresiva incorporación de los juristas como funcionarios del Imperio, es decir, con la vinculación de la jurisprudencia al poder imperial. El Derecho Romano imperial (230-530) supone un cambio radical en los procesos de generación del derecho, así como en la resolución de los conflictos que éste regula y en su validez. Para efectos de la presente investigación, una de sus principales características es la incorporación de los jurisconsultos como funcionarios regulares del Imperio (consilium Principis de Adriano), proceso que empieza con el reconocimiento oficial de ciertos juristas durante la etapa clásica (ius publice respondendi ex auctoritate Principis) y que se caracteriza por la progresiva escrituración de los criterios y decisiones más reconocidos (Edictum, Digesta, entre otros).

Como resultado de este curso histórico, la fuente de su legitimidad muta paulatinamente desde la auctoritas del reconocimiento social de su saber, hacia la potestas que emana del ejercicio del poder político imperial. Así, se consolida un proceso de estandarización de los criterios y procedimientos para la resolución de

9 Sobre las particularidades de la función de los jurisconsultos durante el Derecho Romano clásico, véase IGLESIAS (1989) y GUZMÁN (1996). 
conflictos, que dejan de ser el resultado de su socialización y reconocimiento por la comunidad, para ser determinados unilateralmente por el poder imperial. La principal fuente del derecho deja de ser la jurisprudencia, la que es reemplazada por las constituciones imperiales, configurando un derecho legislado directamente por el emperador.

El creciente estatismo del período unificó tanto el proceso de generación del derecho como su validez, bajo la autoridad imperial, la que se reflejó en el surgimiento de cuerpos normativos oficiales, creados por juristas pero con reconocimiento imperial (Codex $)^{10}$. La jurisprudencia cede ante la legislación en tanto creadora de derecho, limitándose los juristas a compendiar obras del período clásico; su plena burocratización se verifica hacia la segunda mitad del período.

Sin pretender un juicio de valor respecto de ambos modelos y más allá de lo que pueda significar este cambio para efectos de certeza jurídica y unificación del derecho y del propio poder político, me interesa destacar los efectos que pudo haber generado en la comunidad este tránsito desde un sistema socializado de generación del derecho (donde sus criterios son aceptados o cuestionados directamente por los intervinientes), hacia uno en el cual el Derecho y sus criterios comienzan a determinarse verticalmente, sin posibilidad de revisar ciertos criterios o preferir alguno en desmedro de otros. En efecto, cuando la principal fuente del derecho se encuentra condicionada por el reconocimiento social al saber de quién lo genera, la comunidad comprende la función que ella misma cumple en la formación del sistema jurídico, autoconciencia que le permite relacionarse con éste en forma crítica y libre; es decir, la comunidad sabe que coexisten diversos criterios jurídicos y que éstos, a su vez, tienen distintos niveles de validez, factores que no dependen de elementos externos de juicio, sino que emanan de ella misma. Cuando esta etapa termina, la comunidad deja ese papel relevante y asume uno pasivo, en el cual recibe acríticamente el derecho legislado, en el que se impone en forma vertical tanto los criterios de solución de conflictos jurídicos como su propia validez. Se produce una radical transformación en la cultura jurídica de esa comunidad, otrora acostumbrada a ser protagonista del ordenamiento jurídico.

Esta constatación es relevante para la construcción de la cultura jurídica chilena, ya que en tanto herederos del Derecho Romano y de sus formas, la principal influencia radica en el período posclásico, de carácter preferentemente legislado, y no en su etapa clásica. Es decir, nuestra estructura cultural continental se encuen-

10 GuZMÁn (1985). 
tra evidentemente más condicionada por esta última etapa que por la anterior, a diferencia de lo que se podría decir del common law.

\section{b. La recepción del Corpus Iuris Civilis: glosadores y comentaristas}

La etapa del Derecho Romano posclásico termina con la gran recopilación y sistematización de Justiniano, cuyo Corpus Iuris Civilis (CIC) fijó tanto el derecho legislado (Codex Iustiniani) como el jurisprudencial (Digesta). Esta fijación se realizó, principalmente, a través del trabajo de profesores de las universidades de Constantinopla y Berito, generando una suerte de derecho magisterial. Sin embargo, a pesar de la importancia que en sí mismo tiene este proceso en el derecho de Occidente, para efectos de la presente investigación sólo centraré el análisis en su recepción durante la Baja Edad Media.

El CIC fue recepcionado en Occidente en tanto objeto de estudio, pero también en su dimensión de cuerpo normativo; es decir, no sólo fue estudiado en las escuelas de derecho, sino que tuvo validez en tanto derecho vigente (el Sacro Imperio romano-germano, asume la continuidad del derecho vigente en el Imperio romano). El estudio que se hizo del Corpus fue encabezado por las universidades, que se constituyeron en verdaderas escuelas de pensamiento en torno al CIC; desarrolladas principalmente en Italia y Francia, las más importantes se agrupan en Glosadores y Comentaristas ${ }^{11}$. Si bien ambas escuelas comparten su objeto de estudio, lo cierto es que presentan notables diferencias en el tipo de trabajo que realizaban.

La escuela de los Glosadores aparece en Bologna durante el siglo XI y está compuesta por profesores de derecho (encabezados por Irnerio) que se dedicaron al estudio del CIC a través de un particular método de análisis, la glosa: comentarios interlineales o marginales al texto principal, destinados a explicar el significado de sus palabras o de ciertos pasajes. El CIC es una obra de reciente descubrimiento y que ha alcanzado un grado de reconocimiento tal, que el poder político decide aplicarla como derecho vigente. En consecuencia, las escuelas de derecho enseñan y transmiten el CIC como un dogma jurídico: una norma que viene predeterminada, en cuya generación no se ha participado y que debe ser conocida a objeto de difundir su contenido y facilitar su vigencia normativa. La glosa, en tanto género literario, "es determinada por la intangibilidad, por la

${ }^{11}$ Sobre la recepción del Corpus Iuris Civiles en Occidente, véase Bellomo (1996), en especial pp. 123 ss. 
autoridad del texto legislativo y por la técnica exegética empleada para entender sus contenidos" (Bellomo, 1996, p. 142).

Ello puede explicar el uso de esta metodología: se trata de una norma rescatada luego de 600 años y recientemente incorporada al ordenamiento jurídico, redactada por un agente externo a la comunidad que la recibe y a quien se le reconoce gran autoridad. Es lo más cercano al derecho otorgado por una divinidad y, en tanto tal, es intangible: "sería una osadía inadmisible ir más allá de una actividad puramente interpretativa” (Espanha, 2002, p. 109). Por ello, el glosador se relaciona en forma fiel y teórica con el CIC y sólo busca facilitar la inteligibilidad de sus disposiciones, sin criticar o cuestionar los efectos que genera su aplicación ni revisar las posibles alternativas de su configuración y contenido. El glosador tiene una actitud de adoración y respeto ante el CIC, desconociendo sus errores y contradicciones o, incluso, llegando a atribuirlas a su propia incapacidad para comprenderlo.

Hija de los glosadores, la escuela de los Comentaristas profundiza la recepción del Corpus, en un contexto de proliferación de los derechos locales o estatutos en el que el derecho vivido se equipara al emanado de las fuentes clásicas; así, los nuevos juristas no se contentan con facilitar su comprensión a través de la explicación de las disposiciones del CIC, sino que estudian críticamente tanto su contenido temático como su aplicación práctica. A diferencia de la glosa, el comentario (técnica utilizada por esta escuela) se construye a partir de un intercambio de argumentos teóricos y prácticos en torno al CIC, sin asumir a priori su corrección; a partir de cierta distancia intelectual frente al texto (gracias a la incorporación de nuevas categorías lógicas, producto del descubrimiento de textos aristotélicos), desarrolla críticamente su contenido teórico, identificando los problemas de aplicación que sus errores puedan generar ${ }^{12}$.

De esta manera, el comentario trasciende al texto, dando paso al surgimiento de una doctrina o ciencia jurídica a partir del estudio crítico de los temas abordados en el CIC que no se limita a la explicación del sentido de sus palabras o pasajes. El estudio del derecho se amplía a las complejidades de su aplicación práctica y de sus construcciones argumentativas, desembarazándose de la adoración glosadora del CIC. La disposición de nuevos instrumentos intelectuales permite la innovación dogmática de los comentaristas a partir del CIC, ahora complejizado por el afianzamiento de los derechos locales y el consecuente (re)surgimiento de la casuística -y la jurisprudencia- para los problemas en la aplicación del derecho

12 Bellomo (1996), pp. 161-162. 
estatutario $^{13}$. Se trata de una metodología que aborda conjuntos de materias, sin limitarse a la exégesis textual ${ }^{14}$.

En este panorama general que muestran ambas Escuelas, sin perjuicio de sus similitudes, es posible concluir que se constituyen en paradigmas jurídicoculturales diversos: por un lado, el respeto irrestricto por el tenor literal de la norma estudiada, que roza la sumisión intelectual del glosador; por el otro, una distancia crítica a partir de la cual se construye una ciencia jurídica reflexiva y argumentativa. Mientras el glosador presume perfección e intangibilidad en la norma, el comentarista identifica las dificultades prácticas que generan sus propios errores. La voz de la autoridad ahistórica de Justiniano, frente a una construcción argumentativa entre iguales ${ }^{15}$.

Ambos modelos se justifican a partir de sus respectivos contextos históricos, pero lo cierto es que generan efectos diametralmente opuestos sobre la construcción de la cultura jurídica: la intangibilidad de un derecho otorgado por una autoridad distante cede ante la argumentación lógica y crítica de un ordenamiento jurídico complejo que deriva en la construcción de un sistema casuista de soluciones. En cada modelo, la comunidad se relaciona de diferente forma con el ordenamiento jurídico: desde la aceptación acrítica hacia la generación de sus criterios de identificación y validez. Consecuencialmente, la posición del jurista varía en el mismo sentido, desde la sumisión en el primer modelo, hacia una distancia realista en el segundo.

\section{c. El Código Civil chileno: norma fundacional entre dos revoluciones}

El proceso codificador chileno comienza con el Código Civil, promulgado en 1855 y que entra en vigencia en 1857 . La doctrina jurídica nacional ha estudiado profusamente tanto el texto como la codificación que encabeza, principalmente

13 Espanha (2002), pp. 111-115. Respecto a la complejidad del sistema de derecho común, la labor de la ‘jurisprudencia práctica’ y la influencia de juristas como Bartolo de Sassoferrato, véase Bellomo (1996), pp. 206-218.

14 GuZMÁn (1978), p. 28.

15 Si bien la crítica humanista a glosadores y comentaristas es razonable, no fue considerada en este apartado por escapar a los objetivos planteados. El genéricamente denominado mos gallicus asume un supuesto diferente al de estas escuelas: el CIC no es un derecho vigente que deba ser aplicado, sino un documento histórico; GUZMÁN (1978), pp. 30 ss. 
desde las disciplinas dogmático-civilistas, hermenéuticas e históricas ${ }^{16}$. Se trata de una de las normas fundacionales del derecho patrio chileno, hito importante en la progresiva retirada de la vigencia normativa del derecho indiano, proceso que caracteriza al siglo XIX y se consolida a principios del siglo siguiente. Se trata de una norma que impone una nueva regulación sobre aspectos fundamentales de la sociedad, pero principalmente relacionados con los intereses de la clase dirigente (contratos, propiedad, sucesión); dado el bajo nivel de alfabetización y el carácter eminentemente rural de la sociedad de la época, es posible afirmar que se trata de una norma que protege intereses de clase y no sociales. Desde esta perspectiva, es importante destacar algunos aspectos relevantes para una mejor comprensión del papel que cumplió el Código Civil en la formación de la cultura jurídica chilena.

El siglo XIX es determinante para la formación de aquello que hoy denominamos sociedad chilena; se trata de un largo período de transición desde las formas indianas hacia una República más o menos en forma, cuyos procesos normativos se encuentran condicionados por otros de carácter político y sociocultural. Atendiendo a los hitos fundacionales de la historia de Chile podríamos decir que, para estos efectos, el siglo XIX va desde 1810 hasta $1933^{17}$; el Código Civil es promulgado en la década de 1850, un momento de inflexión clave para este proceso.

El autoritarismo que sigue a la Batalla de Lircay (1830), buscó desmantelar los intentos de organización política anterior (pipiola), sustentada en los principios del constitucionalismo naciente y que se manifiesta en una estructura territorial federalizada y una Constitución liberal ${ }^{18}$. Este objetivo se logra a través de estrategias políticas tan diversas como efectivas: la campaña de desacreditación del período anterior (denominada Anarquía por la historiografía conservadora), la mitificación de la figura de Diego Portales a través de una forzada relación entre su

\footnotetext{
16 Un buen ejemplo de la importancia del Código Civil en la dogmática chilena es el texto publicado con ocasión de su sesquicentenario, GUZMÁn (2007b).

17 El sistema constitucional imperante durante el período responde a las premisas impuestas por el bando que triunfó en Lircay y que redactó la Constitución de 1833, con algunas reformas que equilibran el ejercicio del poder en 1873-74. A pesar de las revueltas que originó la cuestión social en la primera década del siglo XX, el cambio constitucional sólo llegó en 1925. La Constitución de ese año alcanzó vigencia normativa efectiva recién en 1933, dando paso a una nueva práctica constitucional, acorde al contexto histórico de la entreguerra. Hay una propuesta muy interesante desde la historia constitucional que debe ser considerada, en Palma (2011).

18 ZÚNiga (2009).
} 
figura y el ordenamiento constitucional de 1833 (tanto la Carta como las normas de excepción ${ }^{19}$ ), entre otras. Se trata de una serie de intervenciones (políticas, normativas, historiográficas) destinadas a fortalecer un modelo conservador y asegurar su permanencia.

El autoritarismo que se impone luego de la batalla de Lircay y, en particular, del estado de sitio decretado con ocasión de la Guerra contra la Confederación Perú-Boliviana, genera importantes resistencias en la sociedad, que se expresan a través de manifestaciones culturales, normativas y levantamientos armados. Como consecuencia de las presiones ejercidas sobre el modelo, éste es transformado progresivamente en un régimen constitucional de corte liberal, que se verifica durante la segunda mitad del siglo XIX.

Este proceso de transformaciones desde el autoritarismo hacia el liberalismo, resultante de las insatisfacciones de una sociedad que presiona sobre el modelo, tiene tres grandes aristas: política, económica y cultural; cada una de ellas se manifestó de diversa manera durante el período en comento. Políticamente, el diseño constitucional original fue significativamente reformado entre 1873 y 1874, alterando la correlación de fuerzas entre los poderes del Estado y terminando con el autoritarismo presidencial que caracterizó a la Constitución de 1833; el reequilibrio entre los poderes del Estado alteró significativamente el proyecto político original, fortaleciendo al Congreso frente al Ejecutivo, permitiendo una práctica política parlamentarizada desde 1891 .

Culturalmente, se registran cambios significativos en materia de libertad de culto, con íconos claramente identificables en la ley de matrimonio para disidentes, la ley interpretativa del artículo $5^{\circ}$ de la Carta, las leyes laicas de 1883-84, la discusión sobre la libertad de enseñanza durante esa misma década y, en fin, la consagración constitucional de la libertad religiosa en 1925. La sociedad avanzó progresivamente desde el catolicismo militante del período indiano hacia las matrices de un Estado laico que garantiza la libertad de culto y de conciencia, tránsito que es posible identificar en la propia estructura del ordenamiento jurídico.

Sin embargo, el período no muestra cambios destinados a modificar la estructura socioeconómica vigente, durante todo el siglo XIX; esta se mantiene prácticamente intacta hasta la reforma agraria de la década de 1960, con algunos conatos de cambio que fueron reprimidos por la élite a principios del siglo XX. Es posible identificar unas manifestaciones incipientes en las reformas introducidas por O'Higgins y que intentaron profundizar los gobiernos de la década de 1820;

19 Criticado en forma muy razonada por PALMA (2002), pp. 45-64. 
pero lo cierto es que la estructura económica de la sociedad se mantuvo durante todo el siglo XIX y buena parte de la centuria siguiente. En esta dimensión, me parece que la promulgación del Código Civil cumple una función clave.

El Código fue promulgado en pleno período de Manuel Montt (18511861), el último gobierno propiamente autoritario de la llamada República Conservadora $^{20}$; es importante destacar que el gobierno de Montt se encuentra históricamente flanqueado por dos levantamientos sociales de carácter armado, en 1851 y 1859 , contra el autoritarismo y el centralismo del régimen vigente ${ }^{21}$. Se trata de un momento de convulsión social e inestabilidad política, durante el cual surgen críticos sociales muy influyentes, que logran organizar significativas manifestaciones públicas contra el modelo. Su presencia y trascendencia en la sociedad chilena de la época alcanza tal relevancia, que el propio poder político se ve obligado a iniciar actividades de autodefensa; por todas, valga el proceso iniciado contra Francisco Bilbao por la crítica social que formula en su escrito "La sociabilidad chilena"22, de 1844.

En este contexto de crítica y convulsión social, el cuestionado gobierno de Montt promulga una norma que rompe con la tradición indiana de aplicación del Derecho y, más importante, congela la regulación normativa de las instituciones más sensibles para sus propios intereses. Al configurar las instituciones económicas más características de la estructura social de la época, a través de una regulación normativa otorgada por el poder político, el Código de Bello vino a protegerlas frente a los procesos de crítica y cambio social. Así, se transforma en una barrera normativa destinada a contener los cambios característicos del siglo XIX, en aquellas materias relacionadas con la estructura económica de la sociedad.

Con disposiciones cargadas de declaraciones políticas, este Código se erige como una verdadera norma fundamental para la organización de la sociedad, al regular materias tan diversas como el ejercicio del poder y el reconocimiento de derechos fundamentales. Así, el sistema de fuentes que recoge el Código en los artículos $1^{\circ}, 2^{\circ}, 3^{\circ}, 7^{\circ}$ y $8^{\circ}$ supone una determinada organización del poder político, estructurada a partir de una clara distribución de competencias entre el

\footnotetext{
20 Respecto a las categorizaciones de la historia político-institucional es posible encontrar diversas posturas; sin embargo, la doctrina está conteste en que los tres primeros decenios son autoritarios (Prieto, Bulnes y Montt), mientras que el cuarto (Pérez) constituye una suerte de transición hacia la República Liberal: HeIsE (1974), pp. 33-35; en un sentido similar, RuIZ-TAGLE (2006), pp. 93-114.

21 Riquelme (1966). Fernández (2007).

22 La más reciente edición de sus obras en Bravo DE GoyeneChe (2007); "La sociabilidad chilena”, en pp. 153-176.
} 
legislador, la judicatura y la comunidad en tanto instancias creadoras de Derecho $^{23}$. 'Con el 'sistema', como con el 'código', la burguesía expresa y se defiende a sí misma. Realiza su más incisiva acción política en el momento mismo que excluye la sociedad y la política de su radio de observación científica" (Bellomo, 1996, p. 17). Por sobre los tribunales y la costumbre de las comunidades locales, prima el derecho legislado como principal fuente del derecho, lo que supone una opción política por parte del Código, que explicita una reacción centralizadora (de carácter normativo y territorial) para privilegia a la élite gobernante de Santiago; las revueltas de 1851 y 1859 son, precisamente, reivindicaciones de poder político encabezadas desde las regiones.

Lo propio sucede con importantes aspectos de la vida individual, que hoy vinculamos a la dignidad de las personas a través del reconocimiento constitucional de los derechos fundamentales, principalmente el derecho de propiedad y la libertad económica. La concepción decimonónica de ambos derechos se encuentra fielmente plasmada en el Código, dando cuenta de lo que hoy llamaríamos una Constitución económica: derechos individuales que generan deberes de abstención respecto de terceros y cuyo ejercicio se garantiza dentro de la esfera inviolable de la vida privada. Una propiedad privada que se ejerce arbitrariamente (art. 582) y sin mención alguna a los límites que le impone su función social, junto a una serie de restricciones metafísicas antes que sociales para la actividad económica (objeto y causa ilícitas), dan cuenta de una concepción de la propiedad y de la economía propia de la separación sistémica entre Estado y sociedad, característica del siglo XIX pero incompatible con el constitucionalismo contemporáneo. Hoy el derecho de propiedad se construye desde su función social (o al menos reconociendo límites en ella), mientras que el ejercicio de actividades económicas encuentra límites en una compleja red normativa que intenta compatibilizar diversos intereses sociales junto al ejercicio de derechos fundamentales, y no sólo en consideraciones metafísicas. En ambos casos, sería posible afirmar que la promulgación de las constituciones del siglo XX supone una suerte de inconstitucionalidad sobreviniente y parcial del Código Civil.

En definitiva, se trata de una norma que contiene cuestiones propiamente constitucionales, plasmando un proyecto político determinado: un Estado centralizado, determinado sistema económico, la homogenización de las regiones y, en definitiva, la consolidación del llamado proyecto portaliano; el Código fue

23 VAlLe (2013). 
un instrumento para el establecimiento de un orden, para enfrentar el complejo proceso de cambios que caracterizó al siglo XIX chileno.

Desde esa perspectiva, el Código fue sacralizado y protegido ante las presiones de la comunidad, ya que una ley 'flexible' habría puesto en peligro el predominio de la élite capitalina por sobre el resto de la sociedad; esta protección se verificó, principalmente, a través de dos vías: las reglas de interpretación de la ley (contenidas en el propio Código) y la doctrina nacional.

a. Las reglas de interpretación que recoge el Código Civil derivan de la escuela histórica de Savigny ${ }^{24}$. Son hijas de un contexto histórico monopolizado por el Estado de Derecho liberal-burgués propio del siglo XIX, en el cual la ley era la máxima expresión del Derecho, generada por un Parlamento socialmente homogéneo como consecuencia del sufragio censitario, donde los conflictos jurídicos no llegaban a tener relevancia constitucional ${ }^{25}$. De esta manera, la pretensión de certeza u objetividad en la interpretación se justifica tanto a partir de la desconfianza reinante hacia la discrecionalidad del juez (que intenta limitarse al vincular su labor a la ley, restándole espacio para decidir), como por la homogeneidad de los intereses que recoge y protege el ordenamiento jurídico.

De esta manera, se asume que existe una interpretación correcta de la ley, aquella que tuvo en consideración el legislador al momento de redactar la norma, la que debe ser develada por el intérprete y respetada por los diversos destinatarios de la norma. Esta tendencia estuvo especialmente presente en los primeros intérpretes del Código Civil chileno que, al entender que el Código acogía un sistema literalista, redujeron el ejercicio de interpretación sólo a las situaciones de oscuridad de la ley ${ }^{26}$, tal como los glosadores del Corpus Iuris Civilis.

El propio enunciado gramatical de estos criterios de interpretación da cuenta de un ejercicio que busca extraer de las entrañas de la norma su verdadero sentido

\footnotetext{
24 Elementos gramatical, sistemático, histórico y teleológico, en SAVIGNY (1840). En todo caso, sálvese el cuestionamiento que de esta teoría se formula en GUZMÁn (2007a), pp. 209-213, ya que según el autor no existe prueba documental fidedigna que permita afirmar que Andrés Bello, redactor del Código Civil chileno, haya seguido los criterios de Savigny. Sin embargo, cuando la escuela historicista ancla la interpretación del derecho al 'espíritu del pueblo' -identificado debidamente por los juristas del pasado- y limita con ello al legislador, viene a confirmar el esfuerzo por naturalizar ciertas decisiones políticas, excluyéndolas de la deliberación (BеLlomo, 1996, p. 21).

En el caso del Código Civil chileno, estas reglas se encuentran enunciadas en los artículos 19 a 24, que data de 1855. Para una revisión de la evolución histórica experimentada por este cuerpo legal, véanse los trabajos recogidos en GUZMÁN (2007b).

25 Zagrebelsky (2003), pp. 29-33.

26 Quintana (2006), pp. 217-220.
} 
o significado, ignorando tanto la posibilidad de conflicto entre diversas interpretaciones, como de evolución en el contenido material de las normas. El recurso al tenor literal, al contexto histórico de generación de la norma, a su espíritu, al espíritu general de la legislación, en fin, a la equidad natural, dan cuenta de un sistema que se construye desde la concepción de una única interpretación posible de la norma y que el intérprete debe buscar.

A este tipo de presupuestos hermenéuticos, subyace cierto concepto del propio ordenamiento jurídico, que pasa por alto que el Derecho es un fenómeno de carácter esencialmente cultural, resultante de las particulares combinaciones de las fuerzas políticas y de poder propias de determinado momento histórico. Así, las reglas de interpretación que se formulan desde esta teoría del ordenamiento jurídico, que privilegia el contexto de generación de las normas por sobre sus contextos de aplicación o de validación, no se formulan para construir el sentido y alcance de las normas a través de un proceso democrático y participativo, sino para su alumbramiento ${ }^{27}$, es decir, para proteger los intereses políticos que motivaron la redacción de la norma en su contexto de generación.

El contenido de los artículos 19 al 24 del Código, constituyen una estrategia institucional para marginar al Derecho vigente del proceso de cambios sociales, minimizando no sólo la función del juez y de la costumbre en el proceso de generación (y validación) del derecho, sino también restringiendo al máximo los márgenes para su interpretación; así, el contenido de la norma se aprende, reproduce y aplica, no se cuestiona. La codificación forma parte del racionalismo imperante en la época, qué duda cabe; sin embargo, me parece que las relaciones de poder político tras estos fenómenos han determinado sus contenidos, generando determinados efectos culturales en la aplicación del derecho que es necesario develar. Existe una relación de poder entre la exégesis, la concepción cognoscitivista de la interpretación y la protección de determinado proyecto político plasmado en la norma, que se esconde tras una pretendida objetividad ${ }^{28}$.

b. La función del Código Civil en la formación de la cultura jurídica chilena ha sido completada por el trabajo de la doctrina, particularmente la contemporánea, determinante para la sacralización e intangibilidad de la norma. Así, Guzmán Brito se refiere a esta norma de la siguiente manera: "vino a superar a todos los códigos de su época, incluso el francés. Por su redacción, el Código de Bello es una alta manifestación de las letras castellanas. Por su sistematización,

27 BASSA (2011a), pp. 19-21.

${ }^{28}$ Foucault (2011b), pp. 37 ss. 
es un modelo de lógica jurídica (...) Por su conceptualización, las ideas vertidas en el código también destacan en su nitidez y claridad. Por su exhaustividad en relación al código francés (...) [ciertas materias] resultaron tratadas en forma completa y satisfactoria" (Guzmán, 1984, pp. 28-29). Remata el autor con un dictamen contundente, que no puede sino condicionar la formación de la cultura jurídica chilena: "Por todas estas razones y muchas otras, ustedes tengan la plena conciencia, como futuros abogados y como chilenos, que el Código Civil de Bello es el monumento legislativo mejor logrado del siglo XIX" (Guzmán, 1984, p. 29). Luego de semejantes calificativos, quién podría cuestionar el contenido de la norma o identificar las finalidades políticas que se persiguen con su promulgación; al contrario, la norma es objeto de respeto e, incluso, veneración. La forma en que se veneran normas emblemáticas del ordenamiento jurídico, que va mucho más allá de las características propias de un sistema jurídico de carácter legislado, sin duda forja una relación de sumisión acrítica entre la norma, sus destinatarios y sus intérpretes.

Este condicionamiento cultural se completa con la posición que se le asigna al juez en el sistema de fuentes, reforzada con la valoración que hace la doctrina al respecto: "El juez debe alejarse del país real, del movido terreno de las personas y las cosas, para refugiarse dentro de un país legal, donde se supone que todo está sujeto a los inamovibles mandatos del gobernante. Sólo así el derecho deja de ser en la práctica un arte de lo justo, abierto a la acción del juez y cristaliza como una mera ciencia de las leyes, cerrada por obra de los gobernantes. Sin duda, esta es la fase más apasionante de la codificación" (Bravo, 1987-88, p. 55). Se trata de un fiel reflejo de los efectos que ha generado la cultura jurídica y cómo ésta se protege y reproduce: ínsita se encuentra una determinada concepción del ordenamiento jurídico, más cercano al derecho otorgado que a su eventual legitimidad democrática, cargada de consideraciones políticas que podrían resumirse en el triunfo de determinado modelo de sociedad que se impone ${ }^{29}$.

\section{LA OBJETIVIDAD EN LA INTERPRETACIÓN DE LOS DERECHOS POR LA PRIMERA DOGMÁTICA CONSTITUCIONAL POSTERIOR A 1980}

La interpretación constitucional de los derechos fundamentales ha sido, durante décadas, un claro ejemplo de los efectos que este transcurso histórico de aceptación acrítica del derecho legislado generó en nuestra cultura jurídica. Uno

29 Bellomo (1996), pp. 11-17. 
de los aspectos más cuidadamente protegidos por la doctrina, desde la objetividad de la interpretación constitucional, ha sido el sistema de garantías de los derechos fundamentales. Con algunas notables (aunque contenidas) excepciones de mutación constitucional ${ }^{30}$ y algunas reformas menores al texto del artículo 19 (principalmente en materia de educación, aunque sin desconocer la importancia de la reforma al artículo $5^{\circ}$ en 1989), el modelo de protección de derechos sigue siendo el mismo que fuera diseñado por la Comisión Ortúzar en 1973-78, con una sobrevaloración de la propiedad y de la libertad. Tanto la interpretación jurisprudencial como dogmática combinaron diversos criterios para configurar su petrificación: originalismo a la chilena, la doctrina del contenido esencial ${ }^{31}$ y la jerarquización de los derechos.

\section{a. La interpretación originalista de la Constitución}

Incorporando el criterio civilista de interpretación de la ley conocido como "historia fidedigna del establecimiento de la norma", la primera doctrina constitucional de las últimas décadas ha petrificado el contenido de la Carta, recurriendo en forma acrítica y permanente a las actas de la Comisión de Estudios para una Nueva Constitución (CENC) ${ }^{32}$, concebidas como fuente de interpretación auténtica.

Esta decisión corresponde a determinada concepción de la Constitución y, en consecuencia, de su interpretación: que el texto es reflejo de un único contenido normativo correcto posible, que puede ser alumbrado con ayuda de las Actas, depositarias de la verdad oficial. Con ello, se ha perpetuado una concepción tanto de la Constitución como de su contenido. Este anquilosamiento en torno a las Actas ha impedido que la sociedad participe democráticamente en la construcción de su ordenamiento iusfundamental, tanto en sede legislativa, como en materia

\footnotetext{
30 La más destacada puede ser el giro hermenéutico en materia de protección de la salud, que se verificó con las sentencias 976 y 1710 del Tribunal Constitucional, que escapan al objetivo de la presente investigación. Otros casos estudiados en NogueIra (2009).

31 Esta perspectiva de la interpretación objetivadora de los derechos fundamentales en Chile, forma parte de la segunda etapa de la presente investigación; por su especificidad, y por tratarse de un elemento clave en la pretensión de objetividad de la interpretación constitucional, será desarrollada en una publicación independiente.

32 Como ejemplos del uso y abuso de las Actas como fuente de interpretación constitucional, particularmente en materia de derechos fundamentales, véase Evans (1999), CEA (2002 y 2007), Verdugo et al. (2002), SilVA (1997-2010).
} 
de interpretación constitucional, protegiendo el contenido material del proyecto constitucional diseñado durante la dictadura.

La función de la Constitución es garantizar la apertura del sistema democrático, a través de la protección de aquellos mínimos necesarios para la convivencia pacífica. En el contexto de una democracia constitucional, una norma fundamental no puede cerrar el sistema a la discusión política para asegurar la permanencia de determinado proyecto político; por el contrario, debe garantizar la apertura para la concretización del contenido de los enunciados normativos ${ }^{33}$. Por el contrario, lo que ha generado la interpretación constitucional originalista es la permanencia del proyecto político de la década de 1970, cerrando el debate democrático con el recurso a la interpretación originalista identificada en las Actas.

Las dos reformas constitucionales más emblemáticas, de 1989 y 2005, modificaron el diseño original, eliminando parte de los enclaves autoritarios destinados a salvaguardar el régimen político diseñado originalmente. Como consecuencia del proceso de reformas constitucionales que se desató en 1989, la Carta vigente está más acerca del actual modelo de Constitución de las democracias occidentales que del diseñado por la dictadura. Las reformas constitucionales han desarticulado la tutela militar sobre el sistema político, así como las principales instituciones a través de las cuales se implementó, tanto en la dimensión orgánica de la Carta como en el diseño del sistema de protección de derechos (aunque los elementos nucleares del sistema económico y político se mantienen a través de las leyes orgánicas constitucionales, que ha excluido ciertas materias del debate público). Sin embargo, se ancló la interpretación de la Carta a las opiniones vertidas en el seno de la CENC, impidiendo que su contenido sea actualizado según evoluciona la sociedad ${ }^{34}$. Ello generó una disociación importante entre la Norma Fundamental y la comunidad que la legitima, lo que redunda en una percepción de la Constitución como Carta Otorgada antes que como una manifestación del autogobierno del pueblo.

En este fenómeno, la interpretación constitucional es clave. La aplicación de todo método de interpretación constitucional se fundamenta en un teoría cons-

\footnotetext{
33 Hesse (2011).

${ }^{34}$ La dogmática constitucional más reciente muestra ya una superación de este criterio hermenéutico, a través de su revisión crítica; aunque los cambios culturales llevan un ritmo diferente, ya es posible notar la influencia de autores como Aldunate (2008), Atria (2007), Contesse (2002), Ruiz-Tagle (2001), Zúniga (2008); cf. BASSA (2011a), p. 36. Algo ha dicho, tímidamente, la jurisprudencia constitucional; cabe destacar el voto de minoría de Hernán Vodanovic en la STC 740, así como parte de los razonamientos de las líneas jurisprudenciales que han abierto las SSTC 976 y 1852.
} 
titucional previa, muchas veces implícita, que resulta decisiva para el resultado de la interpretación. En efecto, la adopción de un determinado método no es una decisión neutra y avalorativa, sino que obedece a una finalidad determinada: que dicho proceso de interpretación llegue a cierto resultado ${ }^{35}$.

Desde esta perspectiva, este originalismo a la chilena (que carece de la fundamentación teórica que podemos encontrar en el modelo estadounidense ${ }^{36}$ ) no sólo es un método de interpretación, sino que es un elemento de una teoría constitucional previa y subyacente a dicho método, que obedece a determinada concepción de la Carta en tanto norma jurídica: la Constitución vigente como el testamento político de la dictadura. Dicha concepción asume que el poder constituyente -que la doctrina identifica en la CENC- ya ha definido el contenido de la Norma Fundamental y los intérpretes deben respetarlo incondicionalmente. Como el contenido de la Carta ya habría sido definido por el titular de la soberanía, no corresponde que por vía de interpretación constitucional se altere el contenido de dicha decisión. Así, la doctrina constitucional mayoritaria había afirmado que la única forma legítima de interpretar la Constitución debe atender a los criterios y parámetros propios del momento histórico identificado como constituyente. Aquí hay mucho más que un empobrecimiento en el desarrollo dogmático de la disciplina a través de una interpretación cognoscitivista ${ }^{37}$. Se trata de una determinada teoría de la interpretación constitucional que utiliza la pretendida objetividad de la norma como un argumento político para obligar a los detractores del proyecto constitucional construido en la década de 1970, y que RuIz-TaGLE enmarca dentro de las denominadas doctrinas pontificias, que se consolidan durante la dictadura de Pinochet ${ }^{38}$.

\section{b. La jerarquización de los derechos}

A pesar que la imposibilidad de jerarquizar a priori los derechos fundamentales forma parte del acervo propio del constitucionalismo contemporáneo ${ }^{39}$, parte

\footnotetext{
35 BASSA (2011b), pp. 285-286.

36 Una conceptualización y relación histórica del originalismo estadounidense en Solum (2011).

37 ATRIA (1998), pp. 371-372, que temprano acusa la falta de un desarrollo de la dogmática constitucional chilena como un elemento que mella la independencia del Tribunal Constitucional, principalmente debido al permanente recurso a las Actas como fuente de interpretación de la Constitución.

38 Ruiz-Tagle (2006), pp. 138-139.

39 En principio, las normas constitucionales que garantizan derechos fundamentales tienen igual jerarquía normativa, dados: 1. la unidad conceptual, sistémica y normativa de la Constitución, 2. que los derechos
} 
importante del constitucionalismo chileno estuvo marcado por los orígenes de la Constitución vigente. Así, son recurrentes las argumentaciones que desconocen el carácter de derechos a diversas declaraciones normativas recogidas en el catálogo de derechos fundamentales del artículo 19, por ejemplo, los derechos sociales ${ }^{40}$, tal como aquella que intentó jerarquizar o los derechos o los valores que éstos representan.

Destacan las afirmaciones de Jaime Guzmán en la CENC, quien ha formado escuela en ciertos sectores políticos y constitucionales. Con una concepción muy limitada de los derechos, los define como "aquellas facultades para cuyo ejercicio, por su titular, sólo requiere que un tercero -sea la autoridad o un particular- no se lo impida o coarte ilegal o arbitrariamente" 41 , aplicando el concepto decimonónico del deber de abstención a todos los derechos. Ello le lleva a concebir todos los derechos sólo como derechos de libertad, como lo afirma respecto de la educación: "en esta materia, se están consagrando dos libertades diferentes: una, que es la libertad de enseñanza y que se va a analizar y considerar más adelante, y otra, que es la libertad de aprendizaje que, en el fondo, se le ha llamado más técnicamente y de manera más adecuada 'derecho a la educación'. Opin[o] que este derecho a la educación es, en esencia, libertad para aprender”². Al invertir el contenido constitucional de los derechos, el autor (y su escuela) desconoce la mayor o menor dimensión prestacional que tienen todos los derechos ${ }^{43}$, dando pie a la negación de algunos de ellos.

fundamentales han sido reconocidos universalmente, atendiendo a demandas históricamente determinadas de ciertos grupos sociales, 3. la igual dignidad de las personas cuyos derechos podrían entrar en colisión, 4. la consecuente imposibilidad de establecer, a priori, preferencias entre la legitimidad de las demandas que históricamente dieron vida a estos derechos, así como entre los intereses concretos de las personas que se enfrentan en una colisión de derechos, 5. la posibilidad que el contenido del catálogo de derechos y de los propios derechos, sea determinado a través de un proceso deliberativo y democrático, impide anclar cualquier concepción que se tenga de los respectivos mandatos normativos, y 6 . la consecuente unidad del catálogo de derechos fundamentales, que atiende a garantizar diversas esferas de realización personal y social.

40 Cf. Martínez, (2006), p. 447 y (2008), pp. 282-283; GÓmez (1993), p. 84: "Si los derechos humanos o esenciales se extienden sin límite a los de primera, segunda y tercera generación y así sucesivamente, la teoría del mercado como asignador de los recursos y la teoría de las decisiones públicas pierden sentido".

41 Rojas et al. (1996), p. 148.

42 Comisión de Estudio de la Nueva Constitución, Actas Oficiales, sesión 139a.

43 Holmes y Sunstein (2011). En el mismo sentido, ZúNigA (2008), p. 87: "la relación de sujetos activopasivo, excede el abanico de facultades propias del derecho subjetivo". 
Existe una inclinación de carácter cultural en la doctrina chilena más tradicional hacia la jerarquización de los derechos reconocidos por la Constitución, que ha tenido eco en la jurisprudencia. La especial combinación de ciertos factores contribuyó a que esta jerarquía de derechos se formulara: 1. las opciones políticas juridificadas en 1980, 2. la sistemática inclinación a la interpretación originalista y 3. la ausencia de un desarrollo de criterios de interpretación propios de los derechos fundamentales, por parte de la doctrina constitucional chilena ${ }^{44}$. Lo anterior nos permitiría explicar por qué se ha recurrido a esta supuesta jerarquía para solucionar aquellos conflictos entre derechos que los criterios clásicos de interpretación no resuelven satisfactoriamente.

En materia de jerarquía de derechos fundamentales, el mismo GuZMán afirmó que "el orden de la Constitución actual [de 1925], no se resguardará convenientemente el orden jerárquico de las garantías" 45 . Esta sola afirmación ha sido suficiente para que parte influyente de la doctrina vea en el catálogo de derechos fundamentales del artículo 19, una pretensión de orden jerárquico por parte del supuesto constituyente que debe ser respetada ${ }^{46}$. La misma postura fue recogida, veinte años después, en similares términos: "quizás alguien podría pensar que [...] basta con reconocer a un derecho su carácter de consubstancial con la naturaleza humana para que todos los que participan de tal rasgo deban valorarse en un pie de igualdad. Nada más inexacto. Comprender la jerarquización que existe entre los distintos niveles o manifestaciones de los diferentes derechos, me parece la clave para un enfoque del tema con auténtico rigor conceptual y, sobre todo, con un indispensable realismo práctico" (RoJAS, 1996, p. 152).

Se ha llegado a afirmar que existe una prelación o jerarquía entre los derechos según su ubicación en el artículo 19 de la Carta ${ }^{47}$, criterio que se constituye como el último parámetro de solución de conflictos entre derechos: si no se logra la conciliación entre los derechos en pugna, "tiene que admitirse la idea de jerarquía o gradación, de primacía o preponderancia de unos sobre otros de esos derechos [...] En ese sentido, creemos que en la enumeración del artículo 19

\footnotetext{
44 A este respecto se ha mostrado un avance importante en Aldunate (2008), y reseña en BASSA (2010).

45 Actas de la Comisión de Estudios de la Nueva Constitución, sesión No 96, de 19 de diciembre de 1974, pp. 30-31. Esta afirmación fue respaldada por el Presidente de la Comisión, Sr. Ortúzar, íd., p. 31.

46 CEA (1999), pp. 173-174.

47 Cea (2012), tomo II, pp. 65-68 y Verdugo et al. (2002), tomo I, pp. 197 y 267: se ha afirmado que la Comisión de Estudios para la Nueva Constitución (1973-78) habría organizado los derechos fundamentales jerárquicamente, atendiendo a los valores que protegen: vida, igualdades y libertades. Para una relación de la situación de la dogmática chilena, véase CONTESSE (2002). También crítico al respecto Celis (2007).
} 
[de la Constitución] no están los derechos al azar, sino que ordenados siguiendo la secuencia jerárquica enunciada. Y lo mismo cabe asegurar del orden con que aparecen asegurados en los Pactos Internacionales respectivos" (Cea, 2012, p. 66). A juicio del autor, la Carta establecería una jerarquía numérica entre los derechos, la que debe ser respetada al momento de resolver los conflictos entre ellos. Antes de la publicación de la primera edición su Derecho Constitucional chileno, Cea ya había afirmado que "tiene que ser reconocida la disparidad de jerarquía entre los derechos esenciales, comenzando con el presupuesto de todos, o sea, la dignidad, para proseguir con la vida e integridad personal" (Cea, 1999, p. 172). Esta jerarquía asume que las colisiones entre derechos son aparentes, permitiendo la construcción hermenéutica de soluciones apriorísticas. Recientemente, el autor ha ratificado su postura, defendiendo la existencia de una jerarquía entre los derechos, la que se fundaría en los conflictos que genera su ejercicio, aunque luego no señala su relación con la jerarquía.

$\mathrm{Ni}$ el recurso a categorías extraculturales de análisis (la igualdad ontológica y deontológica de los derechos, así como la técnica de la ponderación para la solución de colisiones), le permiten desembarazarse de los elementos más característicos de su cultura: el originalismo y la jerarquización. Tanto así, que incluso propone utilizar la jerarquía formal de los derechos como criterio válido para la solución de colisiones entre derechos, en subsidio de la ponderación, perdiendo de vista la evidente incompatibilidad que existe entre ambos criterios: la razonabilidad tras lo pretendido por la ponderación frente al argumento formal de autoridad, irreflexivo, que esconde la jerarquización ${ }^{48}$. Ambas técnicas son, de hecho, incompatibles entre sí.

La influencia de estas ideas puede verificarse en ciertas publicaciones de relevancia, en las cuales es posible identificar afirmaciones tales como: "hubo consenso en la Comisión de que todas las clasificaciones existentes resultaban insatisfactorias y que lo más aconsejable era partir, por orden jerárquico, con el derecho a la vida, las igualdades y las libertades" 49 , o bien, "si aceptamos que los derechos individuales son accesorios de los valores, a los que brindan protección jurídica, y que los valores están ordenados jerárquicamente, debemos concluir que los derechos individuales también están ordenados jerárquicamente. El problema

48 CEA (2012), pp. 68-72.

49 Verdugo et al. (2002), tomo I, p. 197. Sin embargo, el aludido consenso no existió, ya que no hubo un acuerdo al respecto en el seno de la Comisión, al cual se la pudiera adjudicar valor interpretativo de la Constitución: Aldunate (2008), p. 275. 
se reduce entonces a determinar cuál es el orden de los derechos individuales, diseñando una escala jerárquica" (Pfeffer, 1998, p. 225). Sin mayor profundidad en los argumentos, la jerarquía entre los derechos es presentada como una verdad autoevidente; sin embargo, se trata de ideas que van a contrapelo con el constitucionalismo contemporáneo, que entiende al sistema de derechos fundamentales como una unidad en la protección de la persona. El propio Cea lo confirma en la segunda edición de su Derecho Constitucional chileno: "obviamente, en la enumeración del artículo 19 no están los derechos insertados al azar, sino que ordenados siguiendo la secuencia jerárquica enunciada" (CEA, 2012, p. 70); incluso, cita el debate de la CENC, a pesar que los comisionados parecieran discutir sobre técnica legislativa y no sobre la eventual jerarquía ontológica de los derechos.

Parte de la jurisprudencia recogió estas argumentaciones, al adjudicar controversias jurídicas desde la jerarquía entre los derechos, mostrando cuán influyentes han sido estas doctrinas. En la década de 1990 hay dos fallos emblemáticos en este doble sentido: una interpretación originalista que sigue los postulados de la Comisión Ortúzar y la conceptualización de los derechos fundamentales como un orden predeterminado jerárquicamente. En 1993, la Corte de Apelaciones de Santiago, al resolver un amparo por conflicto entre los derechos a la libertad de expresión y a la honra, afirmó lo siguiente: "nadie discute que el constituyente siguió, aunque no lo diga expresamente, un orden de prelación en las garantías y derechos que consagra el artículo 19 [de la Constitución]. Desde luego, la ordenación en que aborda tales derechos y garantías no es arbitraria, como lo prueba la sucesión descendente de su importancia. Así, se comienza con la vida y la integridad personal, luego la igualdad ante la ley, después la igual protección ante la ley y, en seguida, en el número 4, la honra, en circunstancia que la libertad de información está contemplada en el número 12"50. Suerte tuvo la honra de figurar ocho numerales antes que la libertad de información; con ello, asegura protección constitucional ante cualquier conflicto con otro derecho peor ubicado en el catálogo.

Este tipo de teorizaciones dominó el debate constitucional en Chile por tres largas décadas, y sólo comienza a notarse un cambio en ciertos sectores de la doctrina en los últimos lustros. La principal consecuencia de esta situación ha

\footnotetext{
50 Corte de Apelaciones de Santiago, Rol No 983-93, Considerando 8. "Luksic Craig y otros con Martorell Cammarella y otros" [caso inmunidad diplomática], en: Revista de Derecho y Jurisprudencia, tomo XC, II sección V (1993), pp. 164-174. En el mismo sentido, caso La última tentación de Cristo, en: Revista de Derecho y Jurisprudencia, tomo XCIV, II, sección V (1997), pp. 99-116, en el que se protege la honra de Jesucristo porque ésta "prevalece con respecto a la libertad de emitir opinión o de informar", Considerando $14^{\circ}$.
} 
sido impedir el desarrollo dogmático, la realización, de la Constitución chilena. Por el contrario, esta estrategia de interpretación constitucional ancla el contenido normativo de la Carta al período 1973-78, lo que ha impedido concebir plenamente a los derechos fundamentales como diversas manifestaciones de un proceso progresivo y constante de reconocimiento y protección de los intereses y necesidades de las personas. Este proceso intelectual e ideológico que se encuentra detrás de los derechos fundamentales, y que se manifiesta en la competencia política y en la argumentación constitucional ${ }^{51}$, ha sido obstaculizado por las interpretaciones originalistas de la Constitución y la consecuente rigidez del catálogo de derechos, a través de estrategias argumentales como la jerarquización. Es decir, una Constitución que se ha realizado de espaldas al diálogo deliberativo como herramienta fundamental de la democracia.

Replicando la estrategia ínsita en los criterios de interpretación del Código Civil (donde se protege un proyecto de sociedad restringiendo la libertad del intérprete de la norma que lo consagra), la doctrina constitucional ha sostenido que existe cierto 'deber de lealtad' hacia el espíritu de la Carta. Este se manifiesta en un "sometimiento, leal y públicamente demostrado, tanto al espíritu y la letra, como al contexto y los anales fidedignos de cuanto fluye del Bloque [constitucional] mencionado o pueda ser reconducido a él" (Cea, 2006, p. 13), que postula la existencia de un contenido objetivo en la Constitución que debe ser interpretado objetivamente ${ }^{52}$.

Esta afirmación se replica respecto del juez constitucional: "Junto a las virtudes intelectuales se ubican las de índole política, asumiendo que son tales las que demuestran en el Juez Constitucional una conducta de identificación completa con la Constitución al interpretarla y ponerla en acción" (Cea, 2009, p. 81)53. Así, se logra extraer al juez del contexto real a partir del cual se crea una Constitución que, dada la evidente diversidad política y social, no puede obedecer sólo a uno de los variados proyectos de sociedad que emanan de dicha diversidad; sin embargo, se exige que el intérprete (el juez, pero también la doctrina que desarrolla los enunciados normativos) asuma que sólo existe uno y se comprometa con su defensa.

Por ello, en un escenario en el que la doctrina constitucional mayoritaria ha estado abocada a teorizaciones comprometidas con el momento constituyente

51 Ruiz-Tagle (2001), p. 181.

52 En el mismo sentido, Vivanco (2008), p. 561.

53 En el mismo sentido, CeA (2008), pp. 153 ss. 
impulsado por la dictadura y alejadas del constitucionalismo contemporáneo, la jurisprudencia tampoco ha sido capaz de hacer una lectura democrática de la Constitución (quizá con la excepción de la STC 976, que reniega del originalismo). Así, dogmática y jurisprudencia constitucional se han confabulado contra la realización democrática de la Carta, aumentando sostenidamente la brecha entre realidad constitucional y la norma constitucional; la Constitución no da cuenta debidamente del actual consenso constitucional. Este proceso ha contribuido a la situación actual de la Constitución, caracterizada por una fuerte erosión de su legitimidad ante la ciudadanía y de la consecuente pérdida de su dimensión iusfundamental ${ }^{54}$. De ello da cuenta el inacabado proceso de reforma constitucional, que ya desde 2005 registra trece nuevas reformas al texto.

\section{Conclusiones}

1. El devenir histórico que ha dado forma a la cultura jurídica chilena muestra una serie de hitos cuyos paradigmas combinan una generación vertical del derecho (y consecuencialmente sólo un criterio formal de validez), con una aceptación acrítica de un enunciado normativo que se presenta como objetivo.

2. El paradigma jurídico propio de la codificación supone una determinada teoría de la interpretación que, a su vez, asume que el enunciado normativo tiene cierto sentido y alcance que el intérprete debe descubrir, en el marco de las concepciones cognoscitivistas de la hermenéutica jurídica. Así, las reglas de interpretación buscan restringir al máximo la labor del intérprete, garantizando que no cuestionará el contenido del ordenamiento jurídico, erigiéndose como una herramienta para protegerlo de los cambios sociales.

3. La interpretación constitucional temprana al alero de la Carta vigente, combina ambos elementos: un ordenamiento normativo iusfundamental que ha sido generado verticalmente, plasmando determinado proyecto de sociedad protegido por el originalismo a la chilena. Esta estrategia hermenéutica, condiciona culturalmente la relación de la comunidad con la norma constitucional, que la percibe como el reflejo de un contenido verdadero e inmutable. Dado que estas opciones no son políticamente neutras, se percibe una tendencia hacia este tipo de interpretación constitucional en los sectores de la doctrina más cercanos a la dictadura militar, como si se tratara de una estrategia política para proteger el contenido del diseño constitucional original.

54 Sobre la pérdida de la fundamentalidad de la Constitución chilena, véase Aldunate (2005). 
4. El primer período de la doctrina constitucional chilena bajo la Carta vigente, hasta fines del siglo XX, muestra una tendencia hacia la objetivación de la interpretación de los derechos fundamentales, siendo una de las áreas que mejor demuestran los efectos de una cultura jurídica construida desde la pretensión de objetividad. Omitiendo la complejidad propia de enunciados normativos de contenido material abierto e indeterminado, se ha intentado legitimar ciertos criterios hermenéuticos que pretenden objetivar los derechos, anclando su contenido al proyecto político original. Destacan el recurso a la historia fidedigna de la norma y a la pretendida jerarquía entre los derechos como pilares fundamentales de esta pretensión de objetividad, la que ha sido criticada por los sectores de la doctrina más alejados del proyecto constitucional original.

\section{BiBLIOGRAFÍA CITADA}

Aldunate Lizana, Eduardo (2005): "Hacia una Constitución de poca importancia”, en: ZúNiga Urbina, Francisco, Reforma constitucional de 2005 (Santiago, LexisNexis), pp. 67-79.

(2008): Derechos fundamentales, Santiago, LegalPublishing.

(2010): "Aproximación conceptual y crítica al neoconstitucionalismo", en Revista de Derecho, U. Austral de Chile (vol. XXIII, No 1), pp. 79-102.

Atria Lemaitre, Fernando (1998): "El Tribunal Constitucional y la objeción democrática", en Revista Chilena de Derecho, Pontificia Universidad Católica de Chile (vol. XX, No 2-3, tomo I), pp. 367-378.

(2007): Mercado y ciudadanía en la educación, Santiago, Flandes Indiano.

Bassa Mercado, Jaime (2010): Reseña a Aldunate Lizana, Eduardo, Derechos fundamentales (Santiago, LegalPublishing, 2008), en Anuario de Derecho Público, U. Diego Portales, pp. 481-495.

(2011a): "Elementos teóricos para la interpretación constitucional. Algunas reflexiones a propósito de Zagrebelsky y Häberle", en Revista de derechos fundamentales, Universidad Viña del Mar (No 5), pp. 19-21.

(2011b): "Neutralidad política y enseñanza del Derecho Constitucional en Chile", en: Henríquez, Miriam (coord.), Perspectiva del Derecho Constitucional desde el mirador del Bicentenario (Santiago, Asociación Chilena de Derecho Constitucional), pp. 271-289.

Bassa Mercado, Jaime; Viera Álvarez, Christian (2012): "Un nuevo giro hermenéutico de la Corte Suprema en la aplicación del recurso de amparo eco- 
nómico", en Revista de Derecho, P. U. Católica de Valparaíso (vol. XXXVIII, No 1), pp. 611-683.

Bellomo, Manlio (1996): La Europa del Derecho Común, Roma, Il Cigno Galileo Galilei.

Bravo de Goyeneche, José Alberto ed. (2007): Francisco Bilbao. 1823-1865. El autor y la obra, Santiago, Editorial Cuarto Propio.

Bravo LiRA, Bernardino (1987-88): "La codificación en Chile (1811-1907) dentro del marco de la codificación europea e hispanoamericana”, en Revista de Estudios Histórico-Jurídicos (vol. 12), pp. 51-109.

Cea Egaña, José Luis (1998): "Estatuto constitucional de la libertad de información”, en Revista de Derecho, Universidad Católica del Norte (No 5), pp. 15-28.

(1999): El sistema constitucional de Chile: sintesis critica, Santiago, Universidad Austral de Chile.

(2002): Derecho Constitucional chileno, Santiago, Ediciones Universidad Católica, $1^{\mathrm{a}}$ edición, tomo I.

(2006): El nuevo derecho público en la doctrina chilena, Santiago, Cuadernos del Tribunal Constitucional, No 30.

(2007): Derecho Constitucional chileno, Santiago, Ediciones Universidad Católica, $1^{\text {a }}$ edición, tomo II.

(2008): Derecho Constitucional chileno, Santiago, Ediciones Universidad Católica de Chile, $2^{a}$ edición, tomo I.

(2009): Estado social y justicia constitucional, Santiago, Cuadernos del Tribunal Constitucional, No 41.

(2012): Derecho Constitucional chileno, Santiago, Ediciones Universidad Católica de Chile, 2a edición, tomo II.

Celis Danzinger, Gabriel (2007): "Los derechos económicos, sociales y culturales en la interpretación constitucional chilena", en Revista del Doctorado y Magister en Derecho, Universidad de Chile (No 1), pp. 43-74.

CONTESSE SingH, Jorge (2002): "Reglas y principios en Chile: jjerarquía entre los derechos constitucionales?", en Anuario de Filosofia Jurídica y Social (vol. 20), pp. 53-93.

Espanha, António Manuel (2002): Cultura jurídica europea. Sintesis de un milenio, Madrid, Tecnos.

Evans De la CuAdra, Enrique (1993), Los derechos constitucionales, 2a edición actualizada, Santiago, Editorial Jurídica de Chile, 3 tomos. 
Fermandois, Arturo (2006): Derecho Constitucional Económico, 2a edición, Santiago, Ediciones Universidad Católica de Chile.

FERNÁNDEZ, Joaquín (2007): "Mayo de 1859. La caída de Copiapó y el fin de una revolución”, en: AAVV, XIX. Historias del siglo diecinueve chileno (Santiago, Vergara), pp. 161-189.

FouCAult, Michel (2011a): La arqueología del saber, Buenos Aires, Siglo XXI Editores.

FouCAult, Michel (2011b): La verdad y las formas jurídicas, Barcelona, Gedisa Editorial.

Gómez Bernales, Gastón (1993): "Constitución, derechos esenciales y tratados", en Dogmática Constitucional y Derechos Humanos, Cuadernos de Análisis Jurídico No 27, Escuela de Derecho Universidad Diego Portales, Santiago.

Guastini, Riccardo (1999): Distinguiendo. Estudios de teoría y metateoría del Derecho, Barcelona, Gedisa.

GuZmán Brito, Alejandro (1978): "Mos italicus y mos gallicus", en Revista de Derecho, Universidad Católica de Valparaíso (vol. 2), pp. 11-40.

(1984): "La Codificación del Derecho", en Revista de Derecho, Universidad Católica de Valparaíso (vol. 8), pp. 11-30.

(1985): "Codex", en Revista de Estudios Histórico-Jurídicos (vol. X), pp. 107-144.

(1996): Derecho Privado Romano, Santiago, Editorial Jurídica de Chile. (2007a): Las reglas del 'Código Civil' de Chile sobre interpretación de las leyes, Santiago, LexisNexis.

Nexis.

ed. (2007b): El Código Civil de Chile (1855-2005), Santiago, Lexis-

HeIse, Julio (1974): Historia de Chile. El período parlamentario. 1861-1925, Santiago, Editorial Andrés Bello, 1974.

Hesse, Konrad (2011): "Concepto y cualidad de la Constitución”, en Escritos de Derecho Constitucional (Madrid, Centro de Estudios Políticos y Constitucionales), pp. 33-56.

Holmes, Stephen y Sunstein, Cass (2011): El costo de los derechos. Por qué la libertad depende de los impuestos, Buenos Aires, Siglo XXI Editores.

Iglesias, Juan (1989): Las fuentes del Derecho romano, Madrid, Editorial Civitas.

Kennedy, Duncan (2010): Izquierda y derecho, Buenos Aires, Siglo XXI Editores.

MARTí, José Luis (2002): "El realismo jurídico: ¿una amenaza para el liberalismo y la democracia?”, en Isonomía (No 17), pp. 259-282. 